\title{
Toll-Like Receptor 4 Activation in Cancer Progression and Therapy
}

\author{
Alja Oblak ${ }^{1,2}$ and Roman Jerala ${ }^{1,2,3}$ \\ ${ }^{1}$ Department of Biotechnology, National Institute of Chemistry, 1000 Ljubljana, Slovenia \\ ${ }^{2}$ EN-FIST Centre of Excellence, 1000 Ljubljana, Slovenia \\ ${ }^{3}$ Faculty of Chemistry and Chemical Technology, University of Ljubljana, 1000 Ljubljana, Slovenia
}

Correspondence should be addressed to Roman Jerala, roman.jerala@ki.si

Received 1 July 2011; Accepted 1 September 2011

Academic Editor: David Kaplan

Copyright (c) 2011 A. Oblak and R. Jerala. This is an open access article distributed under the Creative Commons Attribution License, which permits unrestricted use, distribution, and reproduction in any medium, provided the original work is properly cited.

Cancer immunotherapy has been the focus of intense research since the late 19th century when Coley observed that bacterial components can contribute to cancer regression by eliciting an antitumor immune response. Successful activation and maturation of tumor-specific immune cells is now known to be mediated by bacterial endotoxin, which activates Toll-like receptor 4 (TLR4). TLR4 is expressed on a variety of immune as well as tumor cells, but its activation can have opposing effects. While TLR4 activation can promote antitumor immunity, it can also result in increased tumor growth and immunosuppression. Nevertheless, TLR4 engagement by endotoxin as well as by endogenous ligands represents notable contribution to the outcome of different cancer treatments, such as radiation or chemotherapy. Further research of the role and mechanisms of TLR4 activation in cancer may provide novel antitumor vaccine adjuvants as well as TLR4 inhibitors that could prevent inflammation-induced carcinogenesis.

\section{Introduction}

Immune system plays a crucial role not only in defense against microbial infection but also in control and surveillance of malignant neoplasms. Immune cells scan tissues with the objective to remove newlyformed malignant cells before they turn into fully formed tumors. Malignant cells developed intricate mechanisms that enable them to inhibit immune cells through secretion of specific cytokines that create an immunosuppressive environment [1]. Tumors can even directly kill tumor-infiltrating lymphocytes, which are CD95 sensitive, by expressing the CD95L (Fas ligand) [2].

Innate immunity is the first line of defense against microbial infection. Innate immune cells recognize the intruding pathogen and trigger appropriate immune response with the help of Toll-like receptors (TLRs), arguably the most important vertebrate innate immune receptors. TLRs recognize different molecules of microbial origin, called pathogenassociated molecular patterns. TLRs are located on the cell surface (TLR1, 2, 4, 5, 6) or in the endosomal compartments (TLR3, 7, 8, 9), where they safeguard the organism against infection. After recognition of their respective ligands, TLRs dimerize and trigger a cytoplasmic signaling pathway that leads to activation of several nuclear factors (e.g., NF $\kappa \mathrm{B}, \mathrm{IRF}$ ) responsible for transcription of immune genes [3].

Toll-like receptor signaling in immune cells is critical for regulation of innate and adaptive immune responses, such as DC maturation and antigen presentation as well as CD8+ T-cell cytotoxicity, all of which are important factors in antitumor immunity [4]. On the other hand, TLR stimulation can also result in enhanced regulatory $\mathrm{T}$ cell proliferation and suppressor function favoring tumor development [5-7]. TLR expression is not limited to immune cells, and indeed many tumor cells have been found to express TLRs, signaling through which can promote tumor growth and immune evasion $[8,9]$. On the other hand, TLR signaling in tumor cells was also shown to reduce the proliferative capacity of tumor cells [10]. We will focus 
on reports concerning TLR4 signaling and its involvement in cancer development and progression as well as the therapeutic benefit that could come from TLR4 stimulation.

\section{Toll-Like Receptor 4 in Health and Disease}

TLRs are homologues of Toll, a receptor found in insects, that is involved in establishing dorsoventral polarity during embryogenesis as well as in immune response against fungal infections [11, 12]. The first discovered human Toll homologue was TLR4. It recognizes endotoxin (i.e., lipopolysaccharide), an outer membrane component of Gram-negative bacteria, that is composed of a conserved amphipathic lipid A component and of variable polysaccharides. The mechanism of TLR4 activation is quite complex and (unlike other TLRs) involves several auxiliary proteins (LBP, CD14) as well as a coreceptor (MD-2) [3] (Figure 1). It is in fact MD-2 and not TLR4 that directly recognizes and binds endotoxin $[13,14]$. MD-2 is a soluble protein with a large hydrophobic pocket that represents the binding site for the acyl chains of lipid A. Lipid A is usually composed of 6 acyl chains, but only 5 of them bind into the hydrophobic pocket of MD-2. The 6th acyl chain protrudes out of the pocket and interacts with hydrophobic residues on TLR4. These interactions are crucial for MD-2/TLR4 heterodimerization and therefore prerequisite for the activation of the TLR4 signaling cascade $[15,16]$. The endotoxin/MD-2/TLR4 heterodimer can, unlike other TLR signaling complexes, recruit two distinct intracellular adaptor proteins (i.e., MyD88/TIRAP and TRIF/TRAM) and can therefore activate two parallel signaling pathways and trigger the transcription of both proinflammatory cytokines as well as type I interferons [3]. Immune effects of TLR4 activation are indeed extensive; LPS alone can activate over 1000 genes [17]. It is therefore not too surprising that TLR4 activation affects not only the immune response against invading Gram-negative bacteria but is also involved in chronic inflammation, autoimmune diseases, and malignancies. TLR4 signaling in cancer is considered a double-edged sword. If TLR4 is activated on immune cells, it can enhance anti-tumor immunity. On the other hand, chronic inflammation is a major risk factor in cancer development [18].

\section{TLR4 Expression in Cancer Cells}

Progress in cancer research over the past decade has been immense, and the original fundamental characteristics of cancer (sustained proliferative signaling, evasion of growth suppressors, resistance to cell death, replicative immortality, induction of angiogenesis, invasion, and metastasis) [19] have recently been revisited and updated. Evasion of immune destruction rises as a new emerging hallmark of cancer [20]. Tumors utilize multiple mechanisms that help them turn the immune balance in their favor. They can secrete immunosuppressive cytokines (TGF $\beta$, IL-10, etc.), express antiapoptotic molecules, or downregulate tumor antigens and $\mathrm{MHC1}$ expression [1]. TLRs are expressed by a variety of tumor cell lines, both in mouse and in human
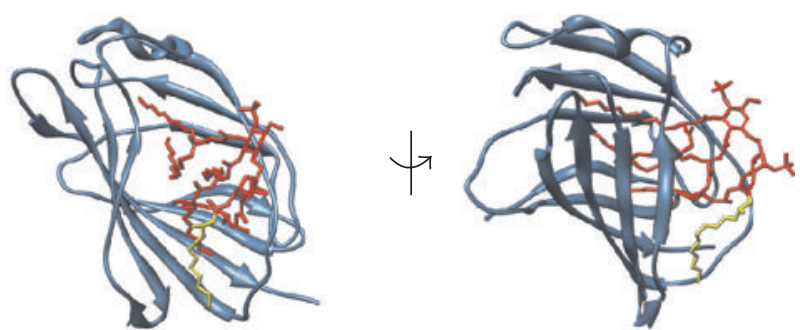

(a)

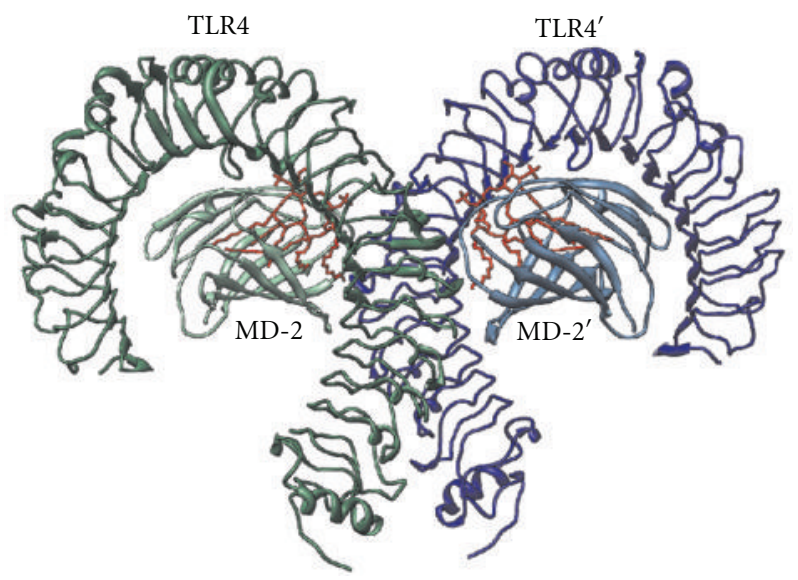

(b)

FIgURE 1: TLR4/MD-2 receptor complex recognizes and binds endotoxin. (a) MD-2 (shown in blue ribbons) is a soluble protein with a large hydrophobic pocket that directly binds bacterial endotoxin (red). One of the acyl chains of endotoxin (yellow) remains outside the hydrophobic pocket and mediates crucial interactions with TLR4 that bind the TLR4/MD-2 heterodimer together. Left: direct view of the MD-2 hydrophobic pocket. Right: side view showing the protruding endotoxin acyl chain. (b) The TLR4/MD2/endotoxin heterodimer. Only the extracellular domains of TLR4 whose crystal structures were determined are shown [16].

TABLE 1: Murine tumor cell lines that express TLR4.

\begin{tabular}{lcc}
\hline Tumor type & Murine tumor cell line & References \\
\hline Breast cancer & 4 T1 & {$[8]$} \\
Colon cancer & MC26 & {$[8]$} \\
Glioma & GL261 & {$[21]$} \\
Lung cancer & LLC1 & {$[8]$} \\
Melanoma & B16 & {$[8]$} \\
Prostate cancer & RM1 & {$[8]$} \\
\hline
\end{tabular}

(Tables 1 and 2). Many of them are not limited to a single TLR but rather utilize an assortment of different TLRs (similarly to immune cells).

Expression of TLR4 was confirmed by RT-PCR and FACS analysis on a large number of murine tumor cells, such as colon, breast, prostate, lung, and melanoma cancer cells. TLR4 signaling was shown to be unimpaired and could induce the synthesis of soluble immune mediators that could help the tumor to withstand the immune attack [8]. MC26 cells, for example, were shown to express functional TLR4 that (when activated by endotoxin) triggered 
TABle 2: Human tumor cell lines that express TLR4.

\begin{tabular}{lcc}
\hline Tumor type & Human tumor cell line & References \\
\hline Bladder cancer & T24 & {$[22]$} \\
Breast cancer & MDA-MB-231 & {$[23]$} \\
Colon cancer & SW480, HT29, KM20 & {$[24,25]$} \\
Laryngeal and oral cancer & PCI-1, PCI-30 & {$[26]$} \\
Melanoma & SkMEL-28, BN1, 9923M, ME5, ME16, ME17 & {$[27,28]$} \\
Neuroblastoma & NB-1 & {$[29]$} \\
Ovarian cancer & SKOV3, AD10, A2780, CP70 & {$[9,30,31]$} \\
\hline
\end{tabular}

activation of NF- $\kappa \mathrm{B}$, ERK, and JNK kinases as well as the synthesis of iNOS, IL-6, and IL-12p70 [8]. iNOS and IL6 have immunosuppressive effects [32-34], but IL-12p70 is generally not considered favorable for tumor development since it activates NK cells, induces T-cell proliferation, and promotes specific allogenic CTL reactions [35]. Some papers indicate that IL-12p70 can also have suppressive effects on allogenic or tumor-specific CTL generation [36, 37], but since evidence undisputedly demonstrates anti-tumor effects for IL-12 its production by tumor cells is possibly just a side product of TLR4 activation and subsequent NF- $\kappa \mathrm{B}$ activation.

Supernatants from endotoxin-stimulated tumor cells were shown to inhibit T-cell proliferation and NK-cell cytotoxicity. Furthermore, blockade of tumor TLR4 signaling with anti-TLR4 siRNA or with inhibitory TLR4 peptide treatment prolongs the survival of MC26-bearing mice [8].

Functional TLR4 signaling was also demonstrated on human tumor cells. On colon carcinoma cells TLR4 signaling, in addition to production of immunosuppressive factors, also improved tumor cell apoptosis resistance [24]. Moreover, endotoxin stimulation of human prostate epithelial cancer cells elicited production of immunosuppressive and proangiogenic factors (TGF-beta and VEGF, resp.) [38].

TLR4 is expressed not only on malignant cells but also on normal tissues and benign tumors [30, 31]. Much remains to be studied concerning the function of TLR4 on normal nonimmune tissues in correlation with cancer development. But we must not forget to examine the expression of other contributing proteins in the TLR4 signaling cascade, for example, the adapter protein MyD88 (myeloid differentiation 88) that is essential for pro-inflammatory signaling. Although TLR4 expression was shown in normal ovarian epithelium, MyD88 was not expressed, therefore rendering TLR4 signaling via the proinflammatory MyD88-dependent pathway nonfunctional $[9,30]$. Similar observation was made in a variety of colorectal carcinoma cell lines where tumor cells expressed TLR4 but failed to coexpress CD14, an important auxiliary protein in the endotoxin receptor complex [39] (Table 3).

\section{Chronic Inflammation Mediated by TLR4 in Cancer Development and Progression}

Numerous links exist between inflammation and tumor development [18]. At the same time inflammatory cytokines
TABle 3: Human tumors expressing TLR4.

\begin{tabular}{lc}
\hline Tumor type & References \\
\hline Adrenocortical cancer & {$[40]$} \\
Breast cancer & {$[41]$} \\
Bladder cancer & {$[22]$} \\
Colon cancer & {$[24,25,39]$} \\
Gastric cancer & {$[42]$} \\
Laryngeal cancer & {$[26]$} \\
Lung cancer & {$[43]$} \\
Melanoma & {$[27,28]$} \\
Neuroblastoma & {$[29]$} \\
Ovarian cancer & {$[9,30,31]$} \\
Prostate cancer & {$[44]$} \\
\hline
\end{tabular}

are indispensable for immune cell activation and antitumor function. Therefore, there is an apparent contradiction when we consider the role of inflammation in cancer. It is plausible that part of the answer to this puzzle lies not in the inflammatory stimulation per se but in its timing, duration, and intensity.

Chronic inflammation is often associated with cancer and can be the result of different causes, such as autoimmune disease or microbial infection.

An example of microbial infection that can predispose an individual to cancer development is Helicobacter pylori infection. Infection with $H$. pylori is a known risk factor in gastric cancer and has been classified as a human carcinogen by the International Agency for Research on Cancer [45]. $H$. pylori infection is chronic and persistent, because $H$. pylori has the ability to evade immune system recognition. It has unusual endotoxin that exhibits very low endotoxic activity compared to the more common hexa-acylated form of endotoxin, usually found in enterobacteria (e.g., Escherichia coli) [46]. In spite of the inability to stimulate TLR4 on its own, $H$. pylori actively promotes inflammation by upregulating TLR4 expression via TLR2 and MEK1/2ERK1/2 pathway giving way to TLR4 activation by endotoxin from other bacteria that pass through the gastrointestinal tract $[47,48]$. TLR4 expression was indeed observed on gastric carcinoma tumor cells as well as on gastric epithelium with intestinal metaplasia and dysplasia [42].

Persistent inflammation is also a characteristic of colitisassociated neoplasms. Patients with ulcerative colitis have a 
five to eight times higher risk of developing colorectal cancer than the rest of the population $[49,50]$. TLR4 expression is upregulated in colitis-associated cancer lesions from patients with ulcerative colitis but not in the surrounding tissue [51]. TLR4 seems to promote the development of colitisassociated colorectal tumors, and mice deficient in TLR4 are markedly protected against the development of neoplasia [52]. The reason behind this phenomenon could lie in the TLR4-Cox2-PGE 2 signaling axis. Cyclooxygenase-2 (Cox-2) is aberrantly expressed in the majority of colorectal tumors and is (along with its enzymatic product prostaglandin $\mathrm{E}_{2}$ ) involved in the development of colorectal cancer [53]. It was recently shown that oral administration of high dosages of $\mathrm{PGE}_{2}$ can by-pass the protective effect exhibited by TLR4deficient mice, which implicates $\mathrm{PGE}_{2}$ as an important TLR4 downstream molecule in colorectal cancer development as well as a potential target for more effective prevention of colitis-associated colorectal cancer [54].

TLR4 also has the potential to become a disease progression marker in patients with colon cancer or premalignant lesions [55] as well as a biomarker of the aggressive tumor phenotype in laryngeal carcinoma and breast cancer [41, 56]. Its high expression correlates with poor prognosis in colorectal cancer patients [57] and in murine models [58]. Furthermore, TLR4 is associated with liver metastasis; researchers showed an increase in TLR4 expression in steatotic murine livers following diet-induced obesity. In a metastatic model of colorectal cancer animals with steatotic livers had increased metastatic tumor mass within the liver compared to lean controls. Silencing of TLR4 on tumors lowered the tumor burden, indicating that tumor cell TLR4 signaling promotes metastatic growth [58]. On the contrary other studies concerning colorectal carcinoma showed correlation between reduced TLR4 expression and increased metastatic potential of the tumor [39].

TLR4 is associated with metastasis also in other types of cancer, such as melanoma, where TLR4 activation induces cell migration [28], and prostate cancer. It was shown that highly metastatic human prostate cancer cell lines, such as PC3 or DU145, express higher levels of TLR4 compared to poorly metastatic cell lines. Moreover, downregulation of TLR4 expression by siRNA can inhibit prostate cancer cell invasion in vitro and can improve survival of tumor-bearing animals [59]. Similar results were shown in human breast cancer cell line, where downregulation of TLR4 significantly reduced tumor cell proliferation [23].

Conversely, another study [60] reports a decrease in TLR4 expression in human prostate tissue samples that correlates with histopathological grade of prostate cancer. TLR4 expressed in normal and low-grade tumors could therefore be a contributing factor in chronic inflammation that promotes carcinogenesis [61], while decreased TLR4 expression in more aggressive high-grade tumors could result from loss of cell differentiation that accompanies cancer progression [60].

A similar phenomenon, though with a different underlying cause, can be seen in the case of cervical cancer, where Yu and coworkers [62] observed downregulation of TLR4 expression during progression of cervical neoplasia. They have attributed this downregulation to the immunosuppressive effect that persistent human papilloma virusinfection has on the host immune response [62]. A degree of prudence is therefore recommended when conclusions are made from the data currently available, because of major discrepancies between studies with respect to different species, cell culture, or cancer type studied.

\section{Endogenous TLR4 Ligands Responsible for TLR4 Signalization in Cancer}

But what activates TLR4 signaling - is it bacterial endotoxin or perhaps other ligands? Endotoxin is ubiquitously present in air, gut, and epithelial surfaces, and perioperative exposure to it is associated with accelerated metastatic tumor growth [63]. Metastases could be the consequence of activation of the TLR4 signaling pathway that results in reduced apoptosis and increased proliferation of metastatic tumor cells. Killeen and coworkers [64] recently studied the role of endotoxin and TLR4 in invasion of extracellular matrix (ECM) and have shown that endotoxin promotes tumor cell ECM adhesion and invasion through activation of the urokinase plasminogen activator system (a serine protease that turns plasminogen into enzymically active plasmin responsible for blood clot degradation).

It is undisputed that the presence or absence of TLR4 expression on tumor (as well as nontumor) cells can influence different stages of carcinogenesis. Although many reports show clear correlation between chronic microbial infection and cancer initiation (e.g., H. pylori infection), others fail to provide evidence of the presence of endotoxin or other TLR4 ligands at cancer initiation sites. An important role is therefore attributed to different molecules of host origin that have lately arisen as potential endogenous ligands of TLR4. These proposed endogenous molecules include different components of the extracellular matrix, intracellular proteins, or modified lipids or lipoproteins (summarized in Table 4). Interestingly, many of them are proposed to activate both TLR4 and TLR2 without having any substantial structural similarity to their natural ligands (endotoxin or lipopeptides, resp.).

Because many (if not most) of the studies describing putative endogenous TLR4 ligands (Table 4) used recombinant proteins and/or commercial reagents with undetermined levels of residual endotoxin, it is reasonable to raise concerns about the purity of the putative ligands used in experiments. The most common methods used to exclude potential endotoxin contamination are the limulus amebocyte lysate (LAL) test and endotoxin neutralization with polymyxin B (PMB). Some researchers demonstrate that their proposed TLR ligands lose their activating capacity after exposure to elevated temperatures. But as described in an excellent review by Erridge [104], these methods have a major shortfall when used in studies describing novel endogenous TLR4 ligands. LAL test, for example, is unable to detect endotoxin in the presence of endotoxin-binding molecules. Furthermore, molecules that bind endotoxin can also prevent its inactivation by PMB. As for the heat 
TABLE 4

\begin{tabular}{|c|c|c|}
\hline $\begin{array}{l}\text { Proposed endogenous TLR4 } \\
\text { ligand }\end{array}$ & & Reference \\
\hline $\begin{array}{l}\text { Advanced glycation end } \\
\text { product low-density } \\
\text { lipoprotein }\end{array}$ & AGE-LDL & {$[65]$} \\
\hline Angiotensin II & & {$[66,67]$} \\
\hline Beta defensin & & {$[68,69]$} \\
\hline Biglycan & & {$[70,71]$} \\
\hline Calprotectin & & [72] \\
\hline Ceramide & & {$[73]$} \\
\hline Fibrinogen & & {$[74,75]$} \\
\hline Fibronectin extra domain A & F-EDA & {$[76,77]$} \\
\hline High-mobility group box 1 & HMGB1 & {$[78-81]$} \\
\hline Heat shock protein & HSP & {$[82-85]$} \\
\hline Heparan sulfate & & {$[86]$} \\
\hline Hyaluronan & & [87-92] \\
\hline $\begin{array}{l}\text { Minimally modified } \\
\text { (oxidized) low-density } \\
\text { lipoprotein }\end{array}$ & $\mathrm{mmLDL}$ & {$[93-95]$} \\
\hline Myeloid-related protein-8/14 & MRP-8/14 & {$[96]$} \\
\hline $\begin{array}{l}\text { Oxidized } \\
\text { Palmitoyl-arachidonoyl- } \\
\text { phosphatidylcholine }\end{array}$ & OxPAPC & {$[97,98]$} \\
\hline $\begin{array}{l}\text { Pancreatic adenocarcinoma } \\
\text { upregulated factor }\end{array}$ & PAUF & {$[99]$} \\
\hline Serum amyloid A & & {$[100]$} \\
\hline Saturated fatty acid & SFA & {$[101]$} \\
\hline Surfactant protein A & & {$[102]$} \\
\hline Tenascin-C & & {$[103]$} \\
\hline
\end{tabular}

sensitivity, the biological activity of endotoxin can be greatly reduced by elevated temperatures.

High-mobility group box-1 protein (HMGB1) is a putative TLR4 ligand implicated in cancer. HMGB1 is a nuclear DNA-binding protein that is actively secreted from cells following cytokine stimulation or passively released during cell death. It signals through the receptor for advanced glycation end products (RAGE) [105] and has been implicated in a variety of immune processes and pathological conditions including cancer $[106,107]$. In the past few years many studies reported signalization of HMGB1 through TLR4 and declared HMGB1 an endogenous ligand of TLR4 $[79,80,107]$. HMGB1 is connected in several ways to tumor progression and metastasis [105]. On the other hand, HMGB1 released from irradiated or doxorubicin/oxaliplatin- treated cells can improve immunogenicity of dying tumor cells and therefore help improve tumor antigen presentation [107]. A substantial number of studies show that HMGB1 however binds agonists of TLR, predominantly anionic molecules such as LPS [108], poly(IC), and CpG ODN that activate TLR4, TLR3, and TLR9; therefore, it may act as a chaperone $[109,110]$, similar to CD14, which stimulates activation of TLR4, TLR3, TLR7, and TLR9 by their agonists [111-113]. Additionally HMGB1 produced in mammalian cell cultures and therefore devoid of bacterial contaminants or endogenous danger signals does not activate TLR4 (unpublished observation). It should therefore be reconsidered whether these TLR4 ligands are not in fact just endotoxin-binding or endotoxin-sensitizing molecules without the intrinsic capability of binding and activating TLR4 on their own [104].

It is difficult to comprehend the multitude of the proposed TLR4 agonists that bear no structural similarity to the lipid A moiety of the LPS that is the only TLR4 agonist that has been prepared by chemical synthesis and whose molecular mechanism of activation is known [15, 16]. With respect to the plausible molecular mechanism of the direct activation of TLR4/MD-2 signaling complex oxidatively modified endogenous lipids seem to be the most likely ubiquitous endogenous agonists (Manček-Keber, manuscript in preparation).

\section{Breaking the Immune Tolerance of Tumors by TLR4 Stimulation}

Toll-like receptor activation is the trigger that sets the immune system into action. The application of TLR ligands in cancer therapy is therefore an attractive possibility that has been intensively studied in the past years in the context of cancer treatment or prevention (as anti-tumor vaccine adjuvants). Macrophages stimulated by endotoxin respond by secretion of chemokines and proinflammatory cytokines, including TNF $\alpha$ and interleukin- $1 \beta$, which coordinate local and systemic inflammatory responses [17]. Dendritic cells, stimulated by endotoxin, secrete IL-12, which is important in anti-tumor immunity [114]. Furthermore, TLR4 stimulation induces DC maturation and antigen presentation, which has important effect on adaptive immune responses [4]. TLR stimulation influences antigen processing and presentation [115] by affecting the expression of costimulatory molecules on the surface of antigen-presenting cells as well as by controlling antigen uptake $[116,117]$ and phagosome maturation [118]. In addition to presenting antigens to lymphocytes, mature DCs are also capable of activating cancerspecific natural killer and NKT cells [119]. Inversely, TLRstimulated NK cells facilitate in immature DC activation and maturation [120] and help intensify DC-mediated antitumor immune responses [121].

Tumors consist in large part not only of tumor but also of immune cells. It is therefore reasonable to assume that direct application of TLR ligands will affect both types of cells. TLR stimulation will possibly have even greater effect on the immune cell population, since not all tumor cells express TLR or the expression varies depending on the developmental stage of the tumor.

This is evident form an example of Bacillus CalmetteGuerin (BCG), an attenuated strain of Mycobacterium bovis that is used in the current treatment of nonmuscle invasive 
bladder cancer [122]. BCG promotes dendritic cell maturation, and this effect is TLR4 (as well as TLR2) dependent [123]. Furthermore, BCG can induce expression of TNFrelated apoptosis-inducing ligand (TRAIL) on tumor infiltrating dendritic cells, therefore rendering them cytotoxic against tumor cells [124].

Another example of an immune activator of microbial origin that promotes dendritic cell maturation is the streptococcal agent OK-432. OK-432 is a preparation of a killed low-virulence strain of Streptococcus pyogenes that has been successfully used for over 30 years as an immunotherapeutic agent in different malignancies [125]. Its mechanism of action apparently involves TLR4 activation, since OKA432 does not inhibit tumor growth on TLR4 knockouts as it does on wild-type mice. Moreover, patients with head and neck cancer responded to OK-432 treatment combined with fluoropyrimidine chemotherapy and radiation significantly better if they expressed TLR4 and MD-2 mRNA (compared to patients without TLR4 or MD-2 expression) $[126,127]$.

Stimulation of TLR4 on tumor cells can give contradicting results in terms of cancer progression versus treatment. The outcome seems to be species, tissue, and tumor type dependent. While TLR4 stimulation is on one hand associated with cancer progression (discussed above), it can also lead to anti-tumor immune response. B16 melanoma cells, for instance, that were stimulated with endotoxin in vitro exhibit reduced capability of inducing tumor growth in vivo. This response was totally independent of TLR4 expression by nontumor cells. In vitro stimulated tumor cells seem to differentially influence the phenotype of tumor infiltrating lymphocytes (TILs) so that TILs produced elevated levels of IFN-gamma and reduced levels of IL-10, thus favorably affecting the intratumoral cytokine balance [10].

\section{Radio- and Chemotherapy Can Enhance Antitumor Immunity by Providing TLR Ligands}

Combining immunotherapy and radiation is a new, compelling approach to cancer therapy. Though radiation is considered mostly immunosuppressive, it is noted also for its immunostimulatory effects. Patients therefore benefit from radiation therapy not only because it directly damages tumor cells but also because suppressor T-cell populations appear to be more radiosensitive than effector $\mathrm{T}$ lymphocytes [128]. Radiation can benefit anti-tumor immunity also by increasing expression of inflammatory cytokines by dendritic cells, therefore affecting their phenotype and function [129]. Dendritic cells are critical for anti-tumor immunity because of their ability to cross-present tumor antigens to specific CD8+ T lymphocytes. For efficient antigen crosspresentation, DCs need to receive appropriate stimulation through innate immune receptors. Since immature DCs can induce anti-tumor immunity when administered into irradiated tumors without the addition of TLR ligands [130], radiation was hypothesized to provide the necessary stimulus.
Apetoh et al. [107] recently proposed that HMGB1, which is released from irradiated tumor cells, acts as an endogenous TLR4 ligand. They demonstrated that TLR4 is essential for efficient tumor antigen cross-presentation following radio- or chemotherapy and proposed that HMGB1 binds and activates TLR4 on DCs. HMGB1 could therefore activate DCs and prevent the accelerated degradation of the phagocytosed tumor antigens within DCs promoting efficient tumor antigen processing and cross-presentation [107] (Figure 2).

The crucial role of TLR4 in immunostimulatory effects of radiation was also emphasized in a study by Paulos et al. [131], where they demonstrated elevated serum levels of endotoxin in mice following whole body irradiation. They showed that microbial endotoxin that translocated from the radiation-injured gut was responsible for enhanced antitumor effect of radiation. Moreover, radiation had diminished effect on tumors following removal of translocated endotoxin or in mice that were defective in the TLR4 signaling pathway [131]. These findings could be especially relevant for the treatment of gastrointestinal malignancies.

\section{Cancer Vaccines Utilizing TLR4 Activation}

Tumor cell lysates or purified tumor-associated antigens for vaccines have been used for therapeutic or prophylactic cancer vaccine. Although cell lysates contain endogenous danger signals that act as adjuvants, strong response against tumor-associated antigens requires additional stimulation of adaptive immune response by Toll-like receptor agonists. Agonists of TLR9 (CpG ODN), TLR3 (poly(IC), and TLR4 (endotoxin analogues) have been used to increase the innate immune response and activate antigen-presenting cells of the host. TLR4 is particularly important for development of a strong adaptive immune response by stimulation of the antibody class switching, affinity maturation, and formation of memory cells [132]. TLR4 is expressed on follicular dendritic cells that are essential for the affinity maturation in germinal centers $[133,134]$. Systemic effect and toxicity of LPS preclude its application for cancer immunotherapy that started by the early attempts by William Coley. MPLA is a monophosphorylated lipid A derivative that has several orders of magnitude lower toxicity than lipid A and was reported to preferentially activate TRIF-dependent pathway [135]. MPLA has been registered as a vaccine adjuvant and used in clinical vaccines, such as Cervarix against human papilomavirus. MPLA is the only TLR4 agonist that has been clinically tested as an adjuvant for cancer vaccines. Results in clinical trials have been modest but seem to be much better if the vaccines are used in early stages of the disease, such as, for example, therapy of non-small-cell lung carcinoma (NSCLC) using MAGE-3 antigen combined with MPLA-based adjuvant AS02B rather than in late stages, when the immune system of patients is already severely compromised (reviewed in [136]). Additional alternative therapeutic approaches are based on combination of TLR4 agonist as a vaccine adjuvant with tumor-associated antigens in combination with radio- or chemotherapy or autologous dendritic cell therapy. 


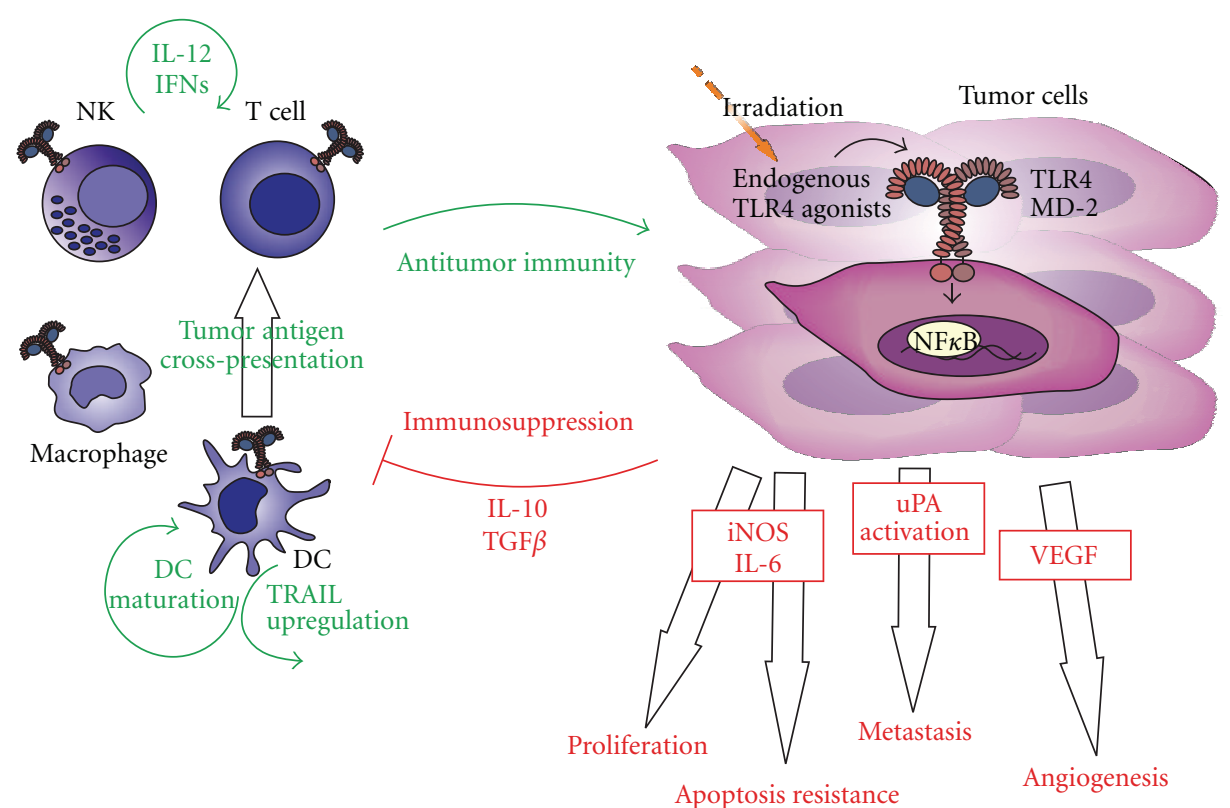

FIGURE 2: TLR4 signaling in cancer-a struggle of antitumor immunity against cancer proliferation and immune evasion. TLR4 signaling on immune cells can enhance anti-tumor immunity by different mechanisms, including IL-12 or IFN $\gamma$ upregulation and promotion of DC maturation and function (left side of the figure, depicted in green). On the other hand, TLR4 signaling on tumor cells can increase their tumorigenic potential (right side of the figure, depicted in red).

\section{Conclusions}

TLR signaling triggers immune cell activation and maturation and is indispensable for the efficient immune response against the pathogenic microorganisms as well as against malignant cells. An effective immune system is most important in the early stages of carcinogenesis when cancerous cells are few and are not limited to less immunogenic cell clones. If immunosurveillance against malignantly transformed cells is unsuccessful in the early stage, tumors quickly outgrow the immune cell cytotoxic capabilities. TLR 4 expression by tumor cells can be a contributing factor that promotes tumor cell proliferation, survival, or immunosuppression.

Therapeutic interventions at the level of TLR4 stimulation is a double-edged sword since different studies demonstrate positive as well as negative effects of TLR4 stimulation on cancer development or treatment. Harnessing the beneficial effects of TLR4 stimulation while eliminating the negative ones remains the challenge for cancer researchers.

\section{Acknowledgments}

This work was supported by program and projects from the Slovenian Research Agency and by the Slovenian centre of excellence EN-FIST.

\section{References}

[1] F. H. Igney and P. H. Krammer, "Immune escape of tumors: apoptosis resistance and tumor counterattack," Journal of Leukocyte Biology, vol. 71, no. 6, pp. 907-920, 2002.

[2] P. R. Walker, P. Saas, and P. Y. Dietrich, "Tumor expression of Fas ligand (CD95L) and the consequences," Current Opinion in Immunology, vol. 10, no. 5, pp. 564-572, 1998.
[3] T. Kawai and S. Akira, "TLR signaling," Cell Death and Differentiation, vol. 13, no. 5, pp. 816-825, 2006.

[4] G. Schreibelt, J. Tel, K. H. E. W. J. Sliepen et al., "Tolllike receptor expression and function in human dendritic cell subsets: implications for dendritic cell-based anti-cancer immunotherapy," Cancer Immunology, Immunotherapy, vol. 59, no. 10, pp. 1573-1582, 2010.

[5] H. Liu, M. Komai-Koma, D. Xu, and F. Y. Liew, "Toll-like receptor 2 signaling modulates the functions of $\mathrm{CD} 4{ }^{+} \mathrm{CD} 25^{+}$ regulatory T cells," Proceedings of the National Academy of Sciences of the United States of America, vol. 103, no. 18, pp. 7048-7053, 2006.

[6] R. P. M. Sutmuller, M. H. M. G. M. den Brok, M. Kramer et al., "Toll-like receptor 2 controls expansion and function of regulatory T cells," Journal of Clinical Investigation, vol. 116, no. 2, pp. 485-494, 2006.

[7] D. Kabelitz, "Expression and function of Toll-like receptors in T lymphocytes," Current Opinion in Immunology, vol. 19, no. 1, pp. 39-45, 2007.

[8] B. Huang, J. Zhao, H. Li et al., "Toll-like receptors on tumor cells facilitate evasion of immune surveillance," Cancer Research, vol. 65, no. 12, pp. 5009-5014, 2005.

[9] M. G. Kelly, A. B. Alvero, R. Chen et al., "TLR-4 signaling promotes tumor growth and paclitaxel chemoresistance in ovarian cancer," Cancer Research, vol. 66, no. 7, pp. 38593868, 2006.

[10] V. Andreani, G. Gatti, L. Simonella, V. Rivero, and M. Maccioni, "Activation of Toll-like receptor 4 on tumor cells in vitro inhibits subsequent tumor growth in vivo," Cancer Research, vol. 67, no. 21, pp. 10519-10527, 2007.

[11] C. Hashimoto, K. L. Hudson, and K. V. Anderson, "The Toll gene of drosophila, required for dorsal-ventral embryonic polarity, appears to encode a transmembrane protein," Cell, vol. 52, no. 2, pp. 269-279, 1988.

[12] B. Lemaitre, E. Nicolas, L. Michaut, J. M. Reichhart, and J. A. Hoffmann, "The dorsoventral regulatory gene cassette 
spatzle/Toll/cactus controls the potent antifungal response in Drosophila adults," Cell, vol. 86, no. 6, pp. 973-983, 1996.

[13] R. Shimazu, S. Akashi, H. Ogata et al., "MD-2, a molecule that confers lipopolysaccharide responsiveness on Toll-like receptor 4," Journal of Experimental Medicine, vol. 189, no. 11, pp. 1777-1782, 1999.

[14] S. Viriyakosol, P. S. Tobias, R. L. Kitchens, and T. N. Kirkland, "MD-2 binds to bacterial lipopolysaccharide," Journal of Biological Chemistry, vol. 276, no. 41, pp. 38044-38051, 2001.

[15] N. Resman, J. Vašl, A. Oblak et al., "Essential roles of hydrophobic residues in both MD-2 and Toll-like receptor 4 in activation by endotoxin," Journal of Biological Chemistry, vol. 284, no. 22, pp. 15052-15060, 2009.

[16] B. S. Park, D. H. Song, H. M. Kim, B. S. Choi, H. Lee, and J. O. Lee, "The structural basis of lipopolysaccharide recognition by the TLR4-MD-2 complex," Nature, vol. 458, no. 7242, pp. 1191-1195, 2009.

[17] H. Björkbacka, K. A. Fitzgerald, F. Huet et al., "The induction of macrophage gene expression by LPS predominantly utilizes Myd88-independent signaling cascades," Physiological Genomics, vol. 19, pp. 319-330, 2005.

[18] A. Mantovani, P. Allavena, A. Sica, and F. Balkwill, "Cancerrelated inflammation,” Nature, vol. 454, no. 7203 , pp. 436 444, 2008.

[19] D. Hanahan and R. A. Weinberg, "The hallmarks of cancer," Cell, vol. 100, no. 1, pp. 57-70, 2000.

[20] D. Hanahan and R. A. Weinberg, "Hallmarks of cancer: the next generation," Cell, vol. 144, no. 5, pp. 646-674, 2011.

[21] O. M. Grauer, J. W. Molling, E. Bennink et al., "TLR ligands in the local treatment of established intracerebral murine gliomas," Journal of Immunology, vol. 181, no. 10, pp. 67206729, 2008.

[22] Y. Qian, J. Deng, H. Xie et al., "Regulation of TLR4-induced IL-6 response in bladder cancer cells by opposing actions of MAPK and PI3K signaling," Journal of Cancer Research and Clinical Oncology, vol. 135, no. 3, pp. 379-386, 2009.

[23] H. Yang, H. Zhou, P. Feng et al., "Reduced expression of Toll-like receptor 4 inhibits human breast cancer cells proliferation and inflammatory cytokines secretion," Journal of Experimental and Clinical Cancer Research, vol. 29, no. 1, article 92, 2010.

[24] X. Y. Tang, Y. Q. Zhu, B. Wei, and H. Wang, "Expression and functional research of TLR4 in human colon carcinoma," American Journal of the Medical Sciences, vol. 339, no. 4, pp. 319-326, 2010.

[25] H. Q. Doan, K. A. Bowen, L. A. Jackson, and B. M. Evers, "Toll-like receptor 4 activation increases Akt phosphorylation in colon cancer cells," Anticancer Research, vol. 29, no. 7, pp. 2473-2478, 2009.

[26] M. Szczepański, M. Stelmachowska, Ł. Stryczyński et al., "Assessment of expression of Toll-like receptors 2, 3 and 4 in laryngeal carcinoma," European Archives of Oto-RhinoLaryngology, vol. 264, no. 5, pp. 525-530, 2007.

[27] M. Molteni, D. Marabella, C. Orlandi, and C. Rossetti, "Melanoma cell lines are responsive in vitro to lipopolysaccharide and express TLR-4," Cancer Letters, vol. 235, no. 1, pp. 75-83, 2006.

[28] Y. Goto, T. Arigami, M. Kitago et al., "Activation of Tolllike receptors 2, 3, and 4 on human melanoma cells induces inflammatory factors," Molecular Cancer Therapeutics, vol. 7, no. 11, pp. 3642-3653, 2008.

[29] F. Hassan, S. Islam, G. Tumurkhuu et al., "Intracellular expression of Toll-like receptor 4 in neuroblastoma cells and their unresponsiveness to lipopolysaccharide," BMC Cancer, vol. 6, article 281, 2006.

[30] M. Szajnik, M. J. Szczepanski, M. Czystowska et al., "TLR4 signaling induced by lipopolysaccharide or paclitaxel regulates tumor survival and chemoresistance in ovarian cancer," Oncogene, vol. 28, no. 49, pp. 4353-4363, 2009.

[31] M. Zhou, M. M. McFarland-Mancini, H. M. Funk, N. Husseinzadeh, T. Mounajjed, and A. F. Drew, "Toll-like receptor expression in normal ovary and ovarian tumors," Cancer Immunology, Immunotherapy, vol. 58, no. 9, pp. 13751385, 2009.

[32] V. Bronte, P. Serafini, A. Mazzoni, D. M. Segal, and P. Zanovello, "L-arginine metabolism in myeloid cells controls T-lymphocyte functions," Trends in Immunology, vol. 24, no. 6, pp. 302-306, 2003.

[33] S. J. Park, T. Nakagawa, H. Kitamura et al., "IL-6 regulates in vivo dendritic cell differentiation through STAT3 activation," Journal of Immunology, vol. 173, no. 6, pp. 3844-3854, 2004.

[34] R. Sun, Z. Tian, S. Kulkarni, and B. Gao, "IL-6 prevents T cellmediated hepatitis via inhibition of NKT cells in $\mathrm{CD} 4^{+} \mathrm{T}$ celland STAT3-dependent manners," Journal of Immunology, vol. 172, no. 9, pp. 5648-5655, 2004.

[35] M. Xu, I. Mizoguchi, N. Morishima, Y. Chiba, J. Mizuguchi, and T. Yoshimoto, "Regulation of antitumor immune responses by the IL-12 family cytokines, IL-12, IL-23, and IL-27," Clinical and Developmental Immunology, vol. 2010, Article ID 832454, 9 pages, 2010.

[36] Y. Nishioka, H. Wen, K. Mitani et al., "Differential effects of IL-12 on the generation of alloreactive CTL mediated by murine and human dendritic cells: a critical role for nitric oxide," Journal of Leukocyte Biology, vol. 73, no. 5, pp. 621629, 2003.

[37] H. K. Koblish, C. A. Hunter, M. Wysocka, G. Trinchieri, and W. M. F. Lee, "Immune suppression by recombinant interleukin (rIL)-12 involves interferon $\gamma$ induction of nitric oxide synthase 2 (iNOS) activity: inhibitors of NO generation reveal the extent of rIL-12 vaccine adjuvant effect," Journal of Experimental Medicine, vol. 188, no. 9, pp. 1603-1610, 1998.

[38] Z. Pei, D. Lin, X. Song, H. Li, and H. Yao, "TLR4 signaling promotes the expression of VEGF and TGF $\beta 1$ in human prostate epithelial PC3 cells induced by lipopolysaccharide," Cellular Immunology, vol. 254, no. 1, pp. 20-27, 2008.

[39] N. Simiantonaki, U. Kurzik-Dumke, G. Karyofylli, C. Jayasinghe, R. Michel-Schmidt, and C. J. Kirkpatrick, "Reduced expression of TLR4 is associated with the metastatic status of human colorectal cancer," International Journal of Molecular Medicine, vol. 20, no. 1, pp. 21-29, 2007.

[40] W. Kanczkowski, P. Tymoszuk, M. Ehrhart-Bornstein, M. P. Wirth, K. Zacharowski, and S. R. Bornstein, "Abrogation of TLR4 and CD14 expression and signaling in human adrenocortical tumors," Journal of Clinical Endocrinology and Metabolism, vol. 95, no. 12, pp. E421-E429, 2010.

[41] S. González-Reyes, L. Marín, L. González et al., "Study of TLR3, TLR4 and TLR9 in breast carcinomas and their association with metastasis," BMC Cancer, vol. 10, article 665, 2010.

[42] B. Schmaußer, M. Andrulis, S. Endrich, H.-K. MüllerHermelink, and M. Eck, "Toll-like receptors TLR4, TLR5 and TLR9 on gastric carcinoma cells: an implication for interaction with Helicobacter pylori," International Journal of Medical Microbiology, vol. 295, no. 3, pp. 179-185, 2005.

[43] Y. B. Zhang, F. L. He, M. Fang et al., "Increased expression of Toll-like receptors 4 and 9 in human lung cancer," Molecular Biology Reports, vol. 36, no. 6, pp. 1475-1481, 2009. 
[44] S. González-Reyes, J. M. Fernández, L. O. González et al., "Study of TLR3, TLR4, and TLR9 in prostate carcinomas and their association with biochemical recurrence," Cancer Immunology, Immunotherapy, vol. 60, no. 2, pp. 217-226, 2011.

[45] R. Pandey, V. Misra, S. P. Misra, M. Dwivedi, A. Kumar, and B. K. Tiwari, "Helicobacter pylori and gastric cancer," Asian Pacific Journal of Cancer Prevention, vol. 11, no. 3, pp. 583$588,2010$.

[46] T. Ogawa, Y. Asai, Y. Sakai et al., "Endotoxic and immunobiological activities of a chemically synthesized lipid A of Helicobacter pylori strain 206-1," FEMS Immunology and Medical Microbiology, vol. 36, no. 1-2, pp. 1-7, 2003.

[47] S. I. Yokota, T. Okabayashi, M. Rehli, N. Fujii, and K. I. Amano, "Helicobacter pylori lipopolysaccharides upregulate Toll-like receptor 4 expression and proliferation of gastric epithelial cells via the MEK1/2-ERK1/2 mitogen-activated protein kinase pathway," Infection and Immunity, vol. 78, no. 1, pp. 468-476, 2010.

[48] B. Su, P. J. M. Ceponis, S. Lebel, H. Huynh, and P. M. Sherman, "Helicobacter pylori activates Toll-like receptor 4 expression in gastrointestinal epithelial cells," Infection and Immunity, vol. 71, no. 6, pp. 3496-3502, 2003.

[49] S. N. Gyde, P. Prior, R. N. Allan et al., "Colorectal cancer in ulcerative colitis: a cohort study of primary referrals from three centres," Gut, vol. 29, no. 2, pp. 206-217, 1988.

[50] J. A. Eaden, K. R. Abrams, and J. F. Mayberry, "The risk of colorectal cancer in ulcerative colitis: a meta-analysis," Gut, vol. 48, no. 4, pp. 526-535, 2001.

[51] M. Fukata, Y. Hernandez, D. Conduah et al., "Innate immune signaling by Toll-like receptor-4 (TLR4) shapes the inflammatory microenvironment in colitis-associated tumors," Inflammatory Bowel Diseases, vol. 15, no. 7, pp. 9971006, 2009.

[52] M. Fukata, A. Chen, A. S. Vamadevan et al., "Toll-like receptor-4 promotes the development of colitis-associated colorectal tumors," Gastroenterology, vol. 133, no. 6, pp. 1869-e2, 2007.

[53] A. Greenhough, H. J. M. Smartt, A. E. Moore et al., "The COX-2/PGE2 pathway: key roles in the hallmarks of cancer and adaptation to the tumour microenvironment," Carcinogenesis, vol. 30, no. 3, pp. 377-386, 2009.

[54] Y. Hernandez, J. Sotolongo, K. Breglio et al., "The role of prostaglandin E2 (PGE 2) in Toll-like receptor 4 (TLR4)mediated colitis-associated neoplasia," BMC Gastroenterology, vol. 10, article 82, 2010.

[55] R. Cammarota, V. Bertolini, G. Pennesi et al., "The tumor microenvironment of colorectal cancer: stromal TLR-4 expression as a potential prognostic marker," Journal of Translational Medicine, vol. 8, article 112, 2010.

[56] K. Starska, E. Forma, I. Lewy-Trenda et al., "The expression of SOCS1 and TLR4-NF $\kappa$ B pathway molecules in neoplastic cells as potential biomarker for the aggressive tumor phenotype in laryngeal carcinoma," Folia Histochemica et Cytobiologica, vol. 47, no. 3, pp. 401-410, 2009.

[57] E. L. Wang, Z. R. Qian, M. Nakasono et al., "High expression of Toll-like receptor 4/myeloid differentiation factor 88 signals correlates with poor prognosis in colorectal cancer," British Journal of Cancer, vol. 102, no. 5, pp. 908-915, 2010.

[58] T. M. Earl, I. B. Nicoud, J. M. Pierce et al., "Silencing of TLR4 decreases liver tumor burden in a murine model of colorectal metastasis and hepatic steatosis," Annals of Surgical Oncology, vol. 16, no. 4, pp. 1043-1050, 2009.
[59] D. Hua, M. Y. Liu, Z. D. Cheng et al., "Small interfering RNAdirected targeting of Toll-like receptor 4 inhibits human prostate cancer cell invasion, survival, and tumorigenicity," Molecular Immunology, vol. 46, no. 15, pp. 2876-2884, 2009.

[60] G. Gatti, A. A. Quintar, V. Andreani et al., "Expression of Toll-like receptor 4 in the prostate gland and its association with the severity of prostate cancer," Prostate, vol. 69, no. 13, pp. 1387-1397, 2009.

[61] S. D. Kundu, C. Lee, B. K. Billips et al., "The Toll-like receptor pathway: a novel mechanism of infection-induced carcinogenesis of prostate epithelial cells," Prostate, vol. 68, no. 2, pp. 223-229, 2008.

[62] L. Yu, L. Wang, M. Li, J. Zhong, Z. Wang, and S. Chen, "Expression of Toll-like receptor 4 is down-regulated during progression of cervical neoplasia," Cancer Immunology, Immunotherapy, vol. 59, no. 7, pp. 1021-1028, 2010.

[63] G. P. Pidgeon, J. H. Harmey, E. Kay, M. Da Costa, H. P. Redmond, and D. J. Bouchier-Hayes, "The role of endotoxin/lipopolysaccharide in surgically induced tumour growth in a murine model of metastatic disease," British Journal of Cancer, vol. 81, no. 8, pp. 1311-1317, 1999.

[64] S. D. Killeen, J. H. Wang, E. J. Andrews, and H. P. Redmond, "Bacterial endotoxin enhances colorectal cancer cell adhesion and invasion through TLR-4 and NF-B-dependent activation of the urokinase plasminogen activator system," British Journal of Cancer, vol. 100, no. 10, pp. 1589-1602, 2009.

[65] C. P. Hodgkinson, R. C. Laxton, K. Patel, and S. Ye, "Advanced glycation end-product of low density lipoprotein activates the Toll-like 4 receptor pathway implications for diabetic atherosclerosis," Arteriosclerosis, Thrombosis, and Vascular Biology, vol. 28, no. 12, pp. 2275-2281, 2008.

[66] Y. Y. Ji, J. T. Liu, N. Liu, Z. D. Wang, and C. H. Liu, "PPAR $\alpha$ activator fenofibrate modulates angiotensin IIinduced inflammatory responses in vascular smooth muscle cells via the TLR4-dependent signaling pathway," Biochemical Pharmacology, vol. 78, no. 9, pp. 1186-1197, 2009.

[67] Y. Ji, J. Liu, Z. Wang, and N. Liu, "Angiotensin II induces inflammatory response partly via Toll-like receptor 4dependent signaling pathway in vascular smooth muscle cells," Cellular Physiology and Biochemistry, vol. 23, no. 4-6, pp. 265-276, 2009.

[68] A. Biragyn, P. A. Ruffini, C. A. Leifer et al., "Toll-like receptor 4 -dependent activation of dendritic cells by $\beta$-defensin 2," Science, vol. 298, no. 5595, pp. 1025-1029, 2002.

[69] A. Biragyn, M. Coscia, K. Nagashima, M. Sanford, H. A. Young, and P. Olkhanud, "Murine $\beta$-defensin 2 promotes TLR-4/MyD88-mediated and NF- $\kappa$ B-dependent atypical death of APCs via activation of TNFR2," Journal of Leukocyte Biology, vol. 83, no. 4, pp. 998-1008, 2008.

[70] L. Schaefer, A. Babelova, E. Kiss et al., "The matrix component biglycan is proinflammatory and signals through Tolllike receptors 4 and 2 in macrophages," Journal of Clinical Investigation, vol. 115, no. 8, pp. 2223-2233, 2005.

[71] A. Babelova, K. Moreth, W. Tsalastra-Greul et al., "Biglycan, a danger signal that activates the NLRP3 inflammasome via Toll-like and P2X receptors," Journal of Biological Chemistry, vol. 284, no. 36, pp. 24035-24048, 2009.

[72] J. M. Ehrchen, C. Sunderkötter, D. Foell, T. Vogl, and J. Roth, "The endogenous Toll-like receptor 4 agonist S100A8/S100A9 (calprotectin) as innate amplifier of infection, autoimmunity, and cancer," Journal of Leukocyte Biology, vol. 86, no. 3, pp. 557-566, 2009.

[73] H. Fischer, P. Ellström, K. Ekström, L. Gustafsson, M. Gustafsson, and C. Svanborg, "Ceramide as a TLR4 agonist; a 
putative signalling intermediate between sphingolipid receptors for microbial ligands and TLR4," Cellular Microbiology, vol. 9, no. 5, pp. 1239-1251, 2007.

[74] S. T. Smiley, J. A. King, and W. W. Hancock, "Fibrinogen stimulates macrophage chemokine secretion through Tolllike receptor 4," Journal of Immunology, vol. 167, no. 5, pp. 2887-2894, 2001.

[75] D. B. Kuhns, D. A. L. Priel, and J. I. Gallin, "Induction of human monocyte interleukin (IL)- 8 by fibrinogen through the Toll-like receptor pathway," Inflammation, vol. 30, no. 5, pp. 178-188, 2007.

[76] Y. Okamura, M. Watari, E. S. Jerud et al., "The extra domain A of fibronectin activates Toll-like receptor 4," Journal of Biological Chemistry, vol. 276, no. 13, pp. 10229-10233, 2001.

[77] S. P. Gondokaryono, H. Ushio, F. Niyonsaba et al., "The extra domain A of fibronectin stimulates murine mast cells via Toll-like receptor 4," Journal of Leukocyte Biology, vol. 82, no. 3, pp. 657-665, 2007.

[78] J. S. Park, D. Svetkauskaite, Q. He et al., "Involvement of Tolllike receptors 2 and 4 in cellular activation by high mobility group box 1 protein," Journal of Biological Chemistry, vol. 279, no. 9, pp. 7370-7377, 2004.

[79] S. P. Jong, F. Gamboni-Robertson, Q. He et al., "High mobility group box 1 protein interacts with multiple Toll-like receptors," American Journal of Physiology, vol. 290, no. 3, pp. C917-C924, 2006.

[80] M. Yu, H. Wang, A. Ding et al., "HMGB1 signals through Toll-like receptor (TLR) 4 and TLR2," Shock, vol. 26, no. 2, pp. 174-179, 2006.

[81] D. Mittal, F. Saccheri, E. Vénéreau, T. Pusterla, M. E. Bianchi, and M. Rescigno, "TLR4-mediated skin carcinogenesis is dependent on immune and radioresistant cells," The EMBO Journal, vol. 29, no. 13, pp. 2242-2252, 2010.

[82] K. Ohashi, V. Burkart, S. Flohé, and H. Kolb, "Cutting edge: heat shock protein 60 is a putative endogenous ligand of the Toll-like receptor-4 complex," Journal of Immunology, vol. 164, no. 2, pp. 558-561, 2000.

[83] A. Asea, M. Rehli, E. Kabingu et al., "Novel signal transduction pathway utilized by extracellular HSP70. Role of Toll-like receptor (TLR) 2 and TLR4," Journal of Biological Chemistry, vol. 277, no. 17, pp. 15028-15034, 2002.

[84] R. M. Vabulas, P. Ahmad-Nejad, S. Ghose, C. J. Kirschning, R. D. Issels, and H. Wagner, "HSP70 as endogenous stimulus of the toll/interleukin-1 receptor signal pathway," Journal of Biological Chemistry, vol. 277, no. 17, pp. 15107-15112, 2002.

[85] R. de Graaf, G. Kloppenburg, P. J. H. M. Kitslaar, C. A. Bruggeman, and F. Stassen, "Human heat shock protein 60 stimulates vascular smooth muscle cell proliferation through Toll-like receptors 2 and 4," Microbes and Infection, vol. 8, no. 7, pp. 1859-1865, 2006.

[86] G. B. Johnson, G. J. Brunn, Y. Kodaira, and J. L. Platt, "Receptor-mediated monitoring of tissue well-being via detection of soluble heparan sulfate by Toll-like receptor 4," Journal of Immunology, vol. 168, no. 10, pp. 5233-5239, 2002.

[87] C. Termeer, F. Benedix, J. Sleeman et al., "Oligosaccharides of hyaluronan activate dendritic cells via Toll-like receptor 4," Journal of Experimental Medicine, vol. 195, no. 1, pp. 99-111, 2002.

[88] K. R. Taylor, J. M. Trowbridge, J. A. Rudisill, C. C. Termeer, J. C. Simon, and R. L. Gallo, "Hyaluronan fragments stimulate endothelial recognition of injury through TLR4," Journal of Biological Chemistry, vol. 279, no. 17, pp. 17079-17084, 2004.
[89] D. Jiang, J. Liang, J. Fan et al., "Regulation of lung injury and repair by Toll-like receptors and hyaluronan," Nature Medicine, vol. 11, no. 11, pp. 1173-1179, 2005.

[90] K. R. Taylor, K. Yamasaki, K. A. Radek et al., "Recognition of hyaluronan released in sterile injury involves a unique receptor complex dependent on Toll-like receptor 4, CD44, and MD-2," Journal of Biological Chemistry, vol. 282, no. 25, pp. 18265-18275, 2007.

[91] S. Gariboldi, M. Palazzo, L. Zanobbio et al., "Low molecular weight hyaluronic acid increases the self-defense of skin epithelium by induction of $\beta$-defensin 2 via TLR2 and TLR4," Journal of Immunology, vol. 181, no. 3, pp. 2103-2110, 2008.

[92] M. Shimada, Y. Yanai, T. Okazaki et al., "Hyaluronan fragments generated by sperm-secreted hyaluronidase stimulate cytokine/chemokine production via the TLR 2 and TLR4 pathway in cumulus cells of ovulated COCs, which may enhance fertilization," Development, vol. 135, no. 11, pp. 2001-2011, 2008.

[93] Y. I. Miller, S. Viriyakosol, C. J. Binder, J. R. Feramisco, T. N. Kirkland, and J. L. Witztum, "Minimally modified LDL binds to CD14, induces macrophage spreading via TLR4/MD2, and inhibits phagocytosis of apoptotic cells," Journal of Biological Chemistry, vol. 278, no. 3, pp. 1561-1568, 2003.

[94] Y. I. Miller, S. Viriyakosol, D. S. Worrall, A. Boullier, S. Butler, and J. L. Witztum, "Toll-like receptor 4-dependent and -independent cytokine secretion induced by minimally oxidized low-density lipoprotein in macrophages," Arteriosclerosis, Thrombosis, and Vascular Biology, vol. 25, no. 6, pp. 1213-1219, 2005.

[95] Y. S. Bae, J. H. Lee, S. H. Choi et al., "Macrophages generate reactive oxygen species in response to minimally oxidized low-density lipoprotein: Toll-like receptor 4- and spleen tyrosine kinase-dependent activation of NADPH oxidase 2," Circulation Research, vol. 104, no. 2, pp. 210-218, 2009.

[96] T. Vogl, K. Tenbrock, S. Ludwig et al., "Mrp8 and Mrp14 are endogenous activators of Toll-like receptor 4, promoting lethal, endotoxin-induced shock," Nature Medicine, vol. 13, no. 9, pp. 1042-1049, 2007.

[97] K. A. Walton, X. Hsieh, N. Gharavi et al., "Receptors involved in the oxidized 1-palmitoyl-2-arachidonoylsn-glycero-3-phosphorylcholine-mediated synthesis of interleukin-8: a role for Toll-like receptor 4 and a glycosylphosphatidylinositol-anchored protein," Journal of Biological Chemistry, vol. 278, no. 32, pp. 29661-29666, 2003.

[98] Y. Imai, K. Kuba, G. G. Neely et al., "Identification of oxidative stress and Toll-like receptor 4 signaling as a key pathway of acute lung injury," Cell, vol. 133, no. 2, pp. 235249, 2008.

[99] H. D. Park, Y. Lee, Y. K. Oh et al., "Pancreatic adenocarcinoma upregulated factor promotes metastasis by regulating TLR/CXCR4 activation," Oncogene, vol. 30, pp. 201-211, 2011.

[100] S. Sandri, D. Rodriguez, E. Gomes, H. P. Monteiro, M. Russo, and A. Campa, "Is serum amyloid A an endogenous TLR4 agonist?" Journal of Leukocyte Biology, vol. 83, no. 5, pp. 1174-1180, 2008.

[101] H. Shi, M. V. Kokoeva, K. Inouye, I. Tzameli, H. Yin, and J. S. Flier, "TLR4 links innate immunity and fatty acid-induced insulin resistance," Journal of Clinical Investigation, vol. 116, no. 11, pp. 3015-3025, 2006.

[102] L. Guillot, V. Balloy, F. X. McCormack, D. T. Golenbock, M. Chignard, and M. Si-Tahar, "Cutting edge: the immunos- 
timulatory activity of the lung surfactant protein-A involves Toll-like receptor 4," Journal of Immunology, vol. 168, no. 12, pp. 5989-5992, 2002.

[103] K. Midwood, S. Sacre, A. M. Piccinini et al., "Tenascin$\mathrm{C}$ is an endogenous activator of Toll-like receptor 4 that is essential for maintaining inflammation in arthritic joint disease," Nature Medicine, vol. 15, no. 7, pp. 774-780, 2009.

[104] C. Erridge, "Endogenous ligands of TLR2 and TLR4: agonists or assistants?" Journal of Leukocyte Biology, vol. 87, no. 6, pp. 989-999, 2010.

[105] G. P. Sims, D. C. Rowe, S. T. Rietdijk, R. Herbst, and A. J. Coyle, "HMGB1 and RAGE in inflammation and cancer," Annual Review of Immunology, vol. 28, pp. 367-388, 2010.

[106] J. E. Ellerman, C. K. Brown, M. de Vera et al., "Masquerader: high mobility group box-1 and cancer," Clinical Cancer Research, vol. 13, no. 10, pp. 2836-2848, 2007.

[107] L. Apetoh, F. Ghiringhelli, A. Tesniere et al., "Toll-like receptor 4-dependent contribution of the immune system to anticancer chemotherapy and radiotherapy," Nature Medicine, vol. 13, no. 9, pp. 1050-1059, 2007.

[108] J. H. Youn, Y. J. Oh, E. S. Kim, J. E. Choi, and J. S. Shin, "High mobility group box 1 protein binding to lipopolysaccharide facilitates transfer of lipopolysaccharide to CD14 and enhances lipopolysaccharide-mediated TNF- $\alpha$ production in human monocytes," Journal of Immunology, vol. 180, no. 7, pp. 5067-5074, 2008.

[109] M.-F. Tsan, "Heat shock proteins and high mobility group box 1 protein lack cytokine function," Journal of Leukocyte Biology, vol. 89, no. 6, pp. 247-852, 2011.

[110] H. S. Hreggvidsdottir, T. Östberg, H. Wähämaa et al., “The alarmin HMGB1 acts in synergy with endogenous and exogenous danger signals to promote inflammation," Journal of Leukocyte Biology, vol. 86, no. 3, pp. 655-662, 2009.

[111] H. K. Lee, S. Dunzendorfer, K. Soldau, and P. S. Tobias, "Double-stranded RNA-mediated TLR3 activation is enhanced by CD14," Immunity, vol. 24, no. 2, pp. 153-163, 2006.

[112] C. L. Baumann, I. M. Aspalter, O. Sharif et al., "CD14 is a coreceptor of Toll-like receptors 7 and 9," Journal of Experimental Medicine, vol. 207, no. 12, pp. 2689-2701, 2010.

[113] S. D. Wright, R. A. Ramos, P. S. Tobias, R. J. Ulevitch, and J. C. Mathison, "CD14, a receptor for complexes of lipopolysaccharide (LPS) and LPS binding protein,” Science, vol. 249, no. 4975, pp. 1431-1433, 1990.

[114] N. Kadowaki, S. Ho, S. Antonenko et al., "Subsets of human dendritic cell precursors express different Toll-like receptors and respond to different microbial antigens," Journal of Experimental Medicine, vol. 194, no. 6, pp. 863-869, 2001.

[115] J. M. Blander and R. Medzhitov, "Toll-dependent selection of microbial antigens for presentation by dendritic cells," Nature, vol. 440, no. 7085, pp. 808-812, 2006.

[116] M. A. West, R. P. A. Wallin, S. P. Matthews et al., "Enhanced dendritic cell antigen capture via Toll-like receptor-induced actin remodeling," Science, vol. 305, no. 5687, pp. 1153-1157, 2004.

[117] W. S. Garrett, L. M. Chen, R. Kroschewski et al., "Developmental control of endocytosis in dendritic cells by Cdc42," Cell, vol. 102, no. 3, pp. 325-334, 2000.

[118] J. M. Blander and R. Medzhitov, "Regulation of phagosome maturation by signals from Toll-like receptors," Science, vol. 304, no. 5673, pp. 1014-1018, 2004.

[119] R. M. Steinman and J. Banchereau, "Taking dendritic cells into medicine,” Nature, vol. 449, no. 7161, pp. 419-426, 2007.
[120] D. M. Andrews, A. A. Scalzo, W. M. Yokoyama, M. J. Smyth, and M. A. Degli-Esposti, "Functional interactions between dendritic cells and NK cells during viral infection," Nature Immunology, vol. 4, no. 2, pp. 175-181, 2003.

[121] T. N. N. Pham, C. Y. Hong, J. J. Min et al., "Enhancement of antitumor effect using dendritic cells activated with natural killer cells in the presence of Toll-like receptor agonist," Experimental and Molecular Medicine, vol. 42, no. 6, pp. 407419, 2010.

[122] R. J. Sylvester, "Bacillus Calmette-Guérin treatment of nonmuscle invasive bladder cancer," International Journal of Urology, vol. 18, no. 2, pp. 113-120, 2011.

[123] S. Tsuji, M. Matsumoto, O. Takeuchi et al., "Maturation of human dendritic cells by cell wall skeleton of Mycobacterium boris bacillus Calmette-Guérin: involvement of Toll-like receptors," Infection and Immunity, vol. 68, no. 12, pp. 68836890,2000

[124] S. Roux, L. Apetoh, F. Chalmin et al., "CD4 $4^{+} \mathrm{CD} 25^{+}$ Tregs control the TRAIL-dependent cytotoxicity of tumorinfiltrating DCs in rodent models of colon cancer," Journal of Clinical Investigation, vol. 118, no. 11, pp. 3751-3761, 2008.

[125] Y. Ryoma, Y. Moriya, M. Okamoto, I. Kanaya, M. Saito, and M. Sato, "Biological effect of OK-432 (Picibanil) and possible application to dendritic cell therapy," Anticancer Research, vol. 24, no. 5C, pp. 3295-3301, 2004.

[126] M. Okamoto, T. Oshikawa, T. Tano et al., "Involvement of Toll-like receptor 4 signaling in interferon- $\gamma$ production and antitumor effect by streptococcal agent OK-432," Journal of the National Cancer Institute, vol. 95, no. 4, pp. 316-326, 2003.

[127] M. Okamoto, T. Oshikawa, T. Tano et al., "Mechanism of anticancer host response induced by OK-432, a streptococcal preparation, mediated by phagocytosis and Toll-like receptor 4 signaling," Journal of Immunotherapy, vol. 29, no. 1, pp. 7886, 2006.

[128] R. J. North, "Radiation-induced, immunologically mediated regression of an established tumor as an example of successful therapeutic immunomanipulation. Preferential elimination of suppressor T cells allows sustained production of effector T cells," Journal of Experimental Medicine, vol. 164, no. 5, pp. 1652-1666, 1986.

[129] A. Shigematsu, Y. Adachi, N. Koike-Kiriyama et al., "Effects of low-dose irradiation on enhancement of immunity by dendritic cells," Journal of Radiation Research, vol. 48, no. 1, pp. 51-55, 2007.

[130] K. W. Kim, S. H. Kim, J. G. Shin et al., "Direct injection of immature dendritic cells into irradiated tumor induces efficient antitumor immunity," International Journal of Cancer, vol. 109, no. 5, pp. 685-690, 2004.

[131] C. M. Paulos, C. Wrzesinski, A. Kaiser et al., "Microbial translocation augments the function of adoptively transferred self/tumor-specific CD8 ${ }^{+} \mathrm{T}$ cells via TLR4 signaling," Journal of Clinical Investigation, vol. 117, no. 8, pp. 21972204, 2007.

[132] S. P. Kasturi, I. Skountzou, R. A. Albrecht et al., "Programming the magnitude and persistence of antibody responses with innate immunity," Nature, vol. 470, no. 7335, pp. 543550, 2011.

[133] A. Garin, M. Meyer-Hermann, M. Contie et al., "Toll-like receptor 4 signaling by follicular dendritic cells is pivotal for germinal center onset and affinity maturation," Immunity, vol. 33, no. 1, pp. 84-95, 2010. 
[134] M. E. M. El Shikh, R. M. El Sayed, Y. Wu, A. K. Szakal, and J. G. Tew, "TLR4 on follicular dendritic cells: an activation pathway that promotes accessory activity," Journal of Immunology, vol. 179, no. 7, pp. 4444-4450, 2007.

[135] V. Mata-Haro, C. Cekic, M. Martin, P. M. Chilton, C. R. Casella, and T. C. Mitchell, "The vaccine adjuvant monophosphoryl lipid A as a TRIF-biased agonist of TLR4," Science, vol. 316, no. 5831, pp. 1628-1632, 2007.

[136] C. W. Cluff, "Monophosphoryl lipid A (MPL) as an adjuvant for anti-cancer vaccines: clinical results," Advances in Experimental Medicine and Biology, vol. 667, pp. 111-123, 2009. 


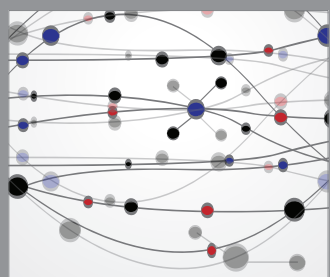

The Scientific World Journal
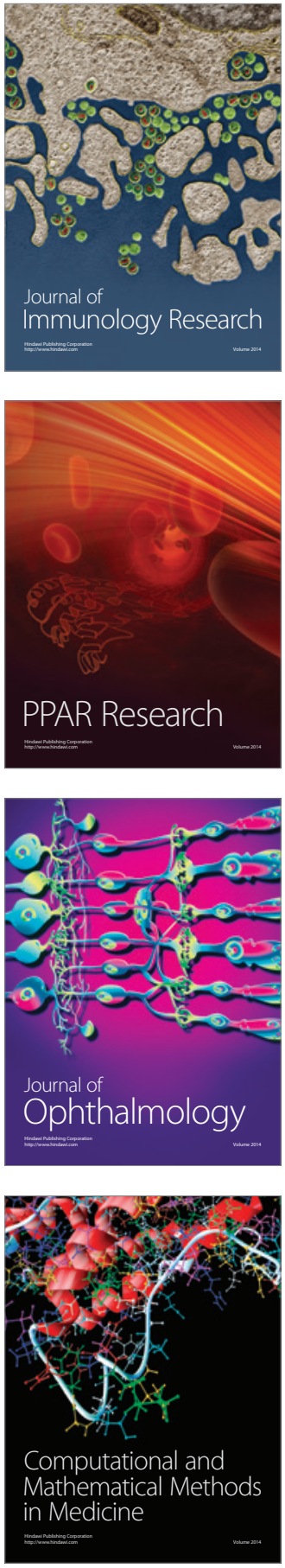

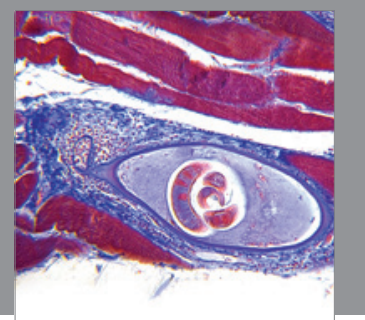

Gastroenterology

Research and Practice
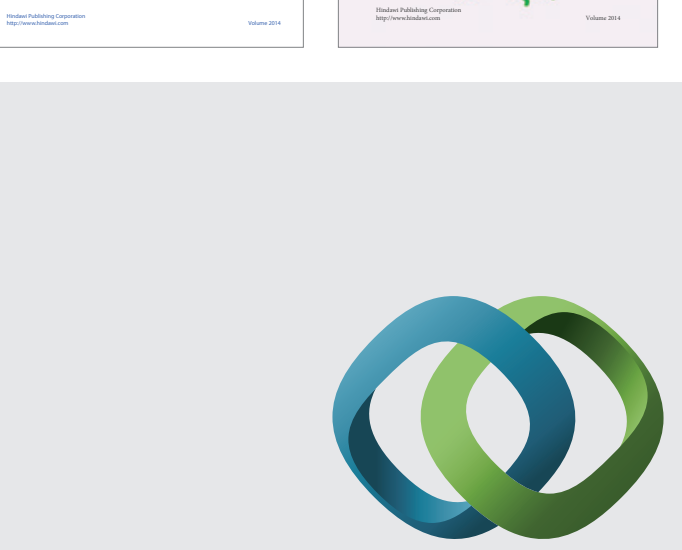

\section{Hindawi}

Submit your manuscripts at

http://www.hindawi.com
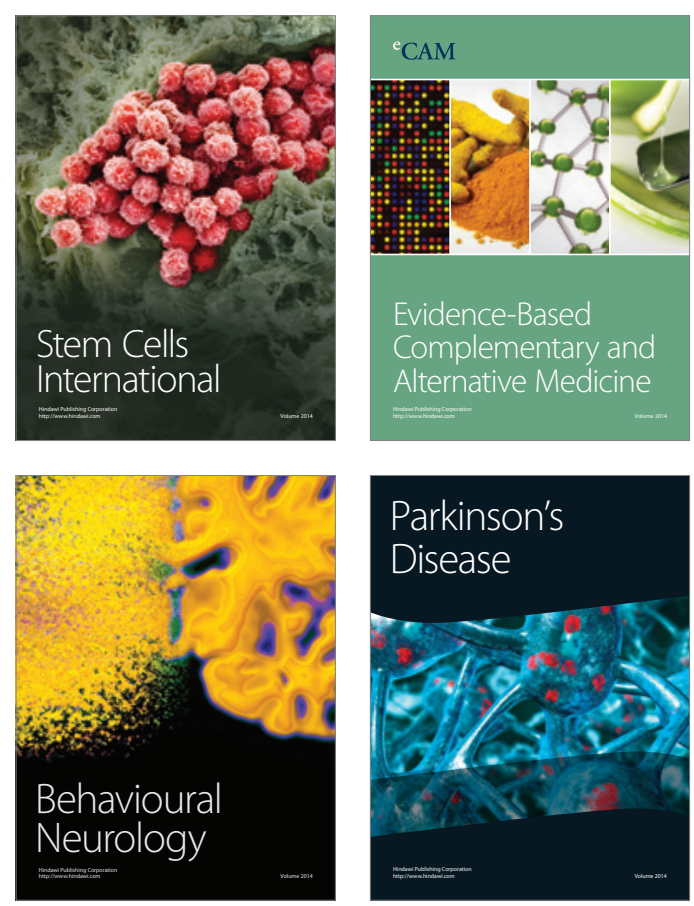

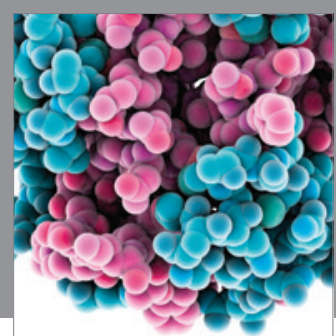

Journal of
Diabetes Research

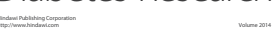

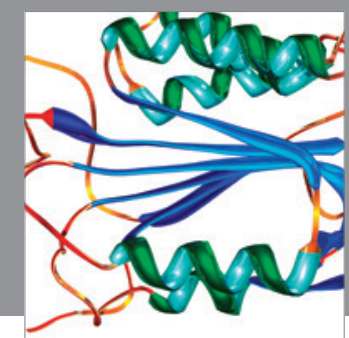

Disease Markers
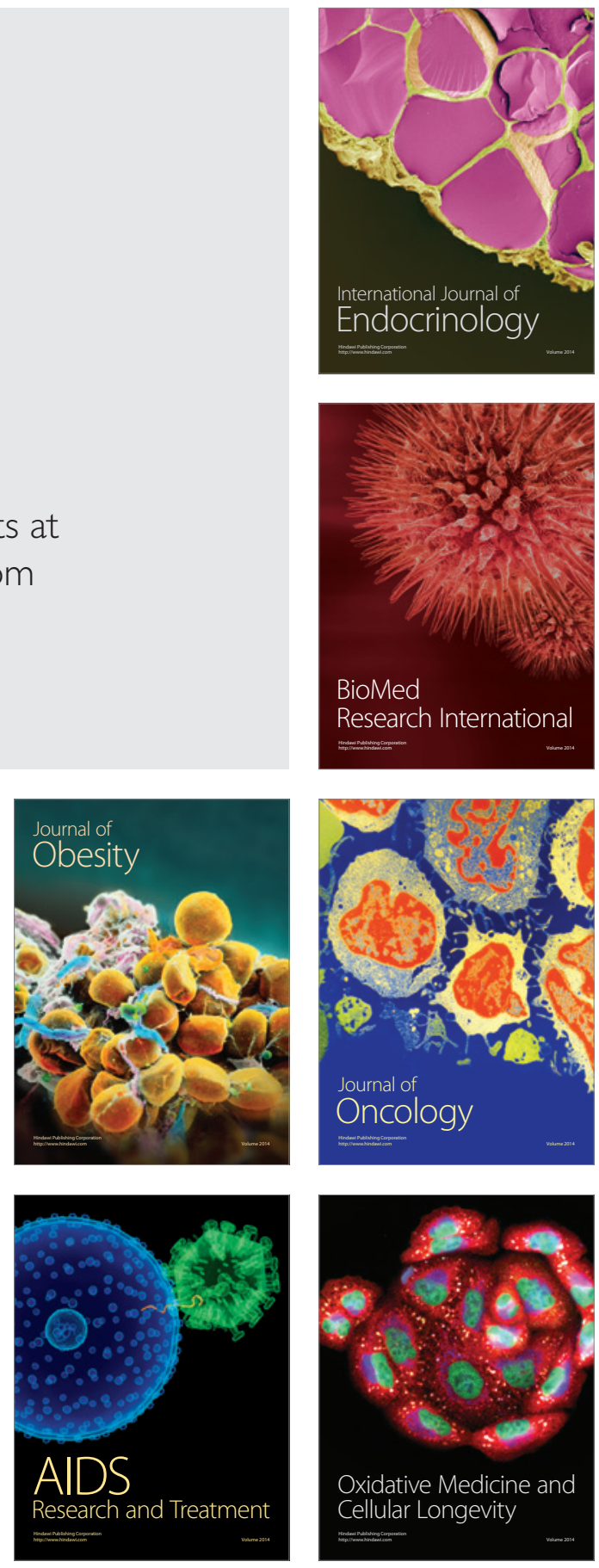